\title{
Dispersal, connectivity, and local conditions determine zooplankton community composition in artificially connected ponds
}

\author{
Hideyuki Doi ${ }^{1,3, *}$, Kwang-Hyeon Chang ${ }^{2,4}$, Shin-ichi Nakano ${ }^{1,5}$ \\ ${ }^{1}$ LAFWEDY, Faculty of Agriculture, Ehime University, 3-5-7, Tarumi, Matsuyama, 790-8566, Ehime, Japan \\ ${ }^{2}$ Center for Marine Environmental Studies (CMES), Ehime University, Bunkyo-cho 2-5, Matsuyama 790-8577, Japan \\ ${ }^{3}$ Present address: Institute for Chemistry and Biology of the Marine Environment, Carl-von-Ossietzky University Oldenburg, \\ Schleusenstrasse 1, 26382 Wilhelmshaven, Germany \\ ${ }^{4}$ Present address: Department of Environmental Science and Engineering, Kyung Hee University, Seochen-dong 1, \\ Giheung-gu, Yongin-Si, Gyeonggi-Do 446-701, Republic of Korea \\ ${ }^{5}$ Present address: Center for Ecological Research, Kyoto University, Hirano 2-509-3, Otsu 520-2113, Shiga, Japan
}

\begin{abstract}
Human-induced increases in ecosystem connectivity can have metacommunity-wide impacts; however, little to no research has tested this assumption. We examined both the mass-effect and species-sorting theories in relation to zooplankton communities in ponds with or without artificial connections to other ponds. We measured the species-abundance composition of the zooplankton community, direct distances between ponds, and several environmental factors (chlorophyll $a_{i}$ Secchi depth, nutrients) in 18 ponds. The results indicated that the zooplankton communities among unconnected ponds were significantly related to environmental and distance factors. In contrast, the communities among connected ponds were not related to any of the predictive factors. Variance in zooplankton species composition was explained by the spatial arrangement of ponds and local environmental conditions. This study demonstrated that artificial connections to other ponds alter the metacommunity structure of zooplankton communities.
\end{abstract}

KEY WORDS: Niche $\cdot$ Pond ecosystem $\cdot$ Rotifer $\cdot$ Cladocerans $\cdot$ Dissimilarity

\section{INTRODUCTION}

Understanding factors that control species diversity in local habitats is a central issue in ecology. This topic has been discussed at length over recent decades, particularly in the context of elucidating mechanisms of biodiversity. Species diversity within ecosystems is often described in terms of the metacommunity concept (Leibold et al. 2004), which is defined as a set of local communities that are linked by the dispersal of multiple, potentially interacting species (Gilpin \& Hanski 1991, Wilson 1992).

Several models describing metacommunities have been proposed (Leibold et al. 2004, Holyoak et al. 2005); the 2 most common, mass effect and species sorting, have been tested in various systems (e.g.
Urban 2004, Thompson \& Townsend 2006, Van de Meutter et al. 2007). The mass-effect model focuses on the effects of immigration and emigration on local population dynamics (Leibold et al. 2004) and assumes that dispersal rates exceed the rate at which environmental conditions exclude taxa, such that migrants influence assemblage composition in recipient habitats (Mouquet \& Loreau 2002). The species-sorting model considers the effect of local environmental patches and species interactions on local community composition (Leibold et al. 2004) and assumes that patterns of biodiversity are closely related to underlying variability in environmental parameters (Leibold \& Miller 2004), such as physico-chemical factors, disturbance, productivity, and interspecific competition (e.g. Tilman 1982, Tokeshi 1999, Yamamoto et al. 2007). 
Many systems are directly connected to other systems. Direct connectivity provides a species pool for the whole community and can alter the community in any one sector (Gonzalez et al. 1998, Gonzalez \& Chaneton 2002, Cottenie \& De Meester 2004). For example, in ponds connected by channels, connectivity affects the resident zooplankton communities (Cottenie et al. 2001, Cottenie $\&$ De Meester 2004). Connectivity can also influence the dispersal rate within metacommunities, and influence several community properties, such as local and regional diversity, and secondary productivity (e.g. Cottenie et al. 2001, Gonzalez \& Chaneton 2002, Cottenie \& De Meester 2004, Vanschoenwinkel et al. 2007).

Natural ecosystem connectivity has been greatly modified by human constructions. For example, rivers and estuaries are now often divided by dams and roads (e.g. Layman et al. 2007, Katano et al. 2009). Such disconnectivity of systems can strongly affect the communities of the disconnected habitats and food webs (e.g. Layman et al. 2007, Katano et al. 2009). Pond ecosystems are often artificially connected through human constructions. Japan harbors many systems of artificially connected ponds, and such increases in connectivity can impart community- and even metacommunity-wide effects due to changes in species' dispersal rates; however, to date, no research has addressed these issues in ecosystems that have been artificially connected by human alteration. Therefore, we hypothesized that anthropogenic influence on the connectivity of ecosystems would affect metacommunity dynamics, since the connectivity of ecosystems is expected to influence dispersal rates and induce passive dispersal within metacommunities. Furthermore, the effects of connectivity, when viewed from the mass-effect and species-sorting metacommunity perspectives, have yet to be examined (but see Van de Meutter et al. 2007).

In the present study, we collected zooplankton community data from 18 ponds (see Appendix 1). Nine of the 18 ponds were artificially connected to another pond via small artificial channels, and the other 9 ponds remained unconnected. The mass-effect theory predicts increasing dissimilarity of invertebrate communities that are spatially distant. On the other hand, the species-sorting perspective predicts that dissimilarity increases when differences in local environmental conditions increase. We examined both theories in relation to zooplankton communities in both connected and unconnected ponds.

\section{MATERIALS AND METHODS}

Study site. The present study was conducted in 18 ponds in Matsuyama, Japan. The ponds are located at $33^{\circ} 48^{\prime}$ to $33^{\circ} 50^{\prime} \mathrm{N}, 132^{\circ} 48^{\prime}$ to $132^{\circ} 55^{\prime} \mathrm{E}$ (50 to $180 \mathrm{~m}$ above sea level) on plains at the foot of a mountain. Fifteen ponds contained the invasive largemouth bass as the top predator, which was introduced in the 1970s to 1980s. We did not observe other piscivorous fish in the ponds, and zooplanktivorous fishes were mainly sunfish and small crucian carp (H. Ohnishi et al. pers. comm., H. Doi pers. obs.).

Connectivity of ponds. Of the 18 ponds, 9 were downstream of another pond, to which they were connected by small artificial channels (connected pond, Fig. 1). The other 9 ponds were upstream of the 9 connected ponds (unconnected pond, Fig. 1). The 9 connected ponds were not connected to each other. The difference in altitude between connected and unconnected ponds was $\sim 40 \mathrm{~m}$. The artificial concrete channels between the ponds were $\sim 100 \mathrm{~m}$ in length (thus the distances between ponds). Water flow was controlled by the water levels of upstream ponds. When the water level of an unconnected (upstream) pond spilled over the channel gate, the surface water drained into the connected ponds via the channels. Unfortunately, no data are available regarding the discharge and current velocity of the channels, but waterflow events occurred several times a year due to heavy rainfall and typhoons. As described above, the surface waters of the ponds rested at different altitudes; thus, water flowed in only one direction: from unconnected (upstream) ponds to connected (downstream) ponds. Preliminary measurements of the differences in location between the unconnected and connected groups indicated that the direct geometric distances between the 9 ponds did not differ significantly between the unconnected and connected groups ( $t$-test, $\mathrm{p}>0.2, \mathrm{n}=$ 72). In addition, the altitudes of the 9 ponds did not significantly differ between the 2 groups ( $t$-test, $\mathrm{p}>$ $0.5, \mathrm{n}=72$ ). All field surveys and samplings were conducted 1 to 3 times from October to November 2005.

Zooplankton sample collection. Zooplankton are commonly used to address metacommunity-level questions (e.g. Cottenie et al. 2001, Cottenie \& De Meester 2004, Van de Meutter et al. 2007); their rapid generation times make them especially suitable for examining metacommunities as short-term sampling methods can be used. Crustacean zooplankton were collected by

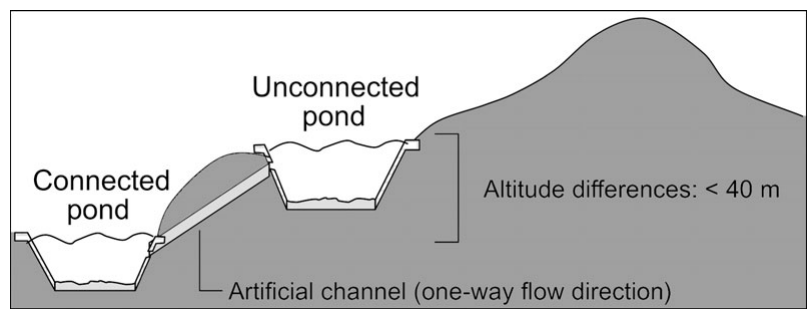

Fig. 1. Schematic illustration of the connected and unconnected ponds 
3 to 5 hauls of a vertical net with a $200 \mu \mathrm{m}$ mesh from near the bottom to the surface of each pond. For collection of rotifers and copepod nauplii, we used a column sampler with a hydraulically operated flap at the bottom, designed for collecting water from the surface to a certain depth. Water was collected 3 to 5 times from the surface to $1 \mathrm{~m}$ depth and was then filtered through a $40 \mu \mathrm{m}$ mesh net. All samples from both methods were pooled to generate total abundance data from replicate samples. Zooplankton were preserved in formalin at a final concentration of $\sim 5 \%$. The fixed zooplankton samples were concentrated to $20 \mathrm{ml}$ by settling for $24 \mathrm{~h}$. Depending on the absolute abundance of zooplankton, samples were either entirely identified and counted or were subsampled. We separately counted cladocerans and copepods without nauplii from the $200 \mu \mathrm{m}$ net sample, and rotifers, small forms of cladocerans (i.e. juvenile Bosmina <200 $\mu \mathrm{m}$ ) and copepod nauplii from the column sampler. Zooplankton species were identified and counted under light microscopy at $200 \times$ to the lowest taxonomic level possible. The resolution of Copepoda was to the near-genus level, and that of other groups was to the species or genus level.

Measurements of local ecological conditions. To determine chlorophyll a ( $\mathrm{chl}$ a) concentrations, $250 \mathrm{ml}$ of surface water (0 to $50 \mathrm{~cm}$ depth) were collected using the column sampler and then filtered through a $0.2 \mu \mathrm{m}$ Nuclepore filter to retain seston. The filter was then placed in a glass test tube, and N,N-dimethylformamide was added to extract $\mathrm{chl} a$. Chl a concentrations were determined using a fluorometer (10-AU, Turner Designs) following Moran \& Porath (1980).

To determine the abundances of heterotrophic nanoflagellates (HNF) and bacteria, two $100 \mathrm{ml}$ aliquots of surface water ( 0 to $50 \mathrm{~cm}$ ) were collected using the column sampler. The water samples were fixed in glutaraldehyde to a final concentration of $1 \%$. Bacteria and HNF were counted under epifluorescence microscopy with ultraviolet excitation (excitation wavelength of 330 to $385 \mathrm{~nm}$ ) using DAPI (Porter \& Feig 1980) and primulin (Caron 1983) staining methods, respectively.

The $\mathrm{pH}$ and electrical conductivity of the surface water were measured using the portable meters, Twin-pH and Twin-Cond (Horiba). Nutrient concentrations in the surface water $\left(\mathrm{NH}_{4}{ }^{+}, \mathrm{NO}_{2}{ }^{-}+\mathrm{NO}_{3}{ }^{-}, \mathrm{PO}_{4}{ }^{3-}, \mathrm{Si}: \mathrm{O}_{2}{ }^{-}\right)$were determined using colorimetric analysis with a continuous flow system (AutoAnalyzer 3, Bran+Luebbe). Dissolved organic carbon (DOC) was measured by a total organic carbon meter (TOC 5000, Shimazu). We also measured Secchi depth at the center of each pond.

Statistical analyses. The datasets from the connected and unconnected ponds were analyzed separately to estimate the effects of connectivity in terms of both the mass-effect and species-sorting hypotheses. Five potential predictor matrices were extracted from the data: All,
Water, Food, Size, and Distance. For the All condition, all of the ecological data (Appendix 1) were standardized and reduced to a matrix of Euclidean dissimilarities between sites. For the Water condition, data on nutrients, Secchi depth, $\mathrm{pH}$, electronic conductivity (EC), and DOC were also reduced to a dissimilarity matrix. For the Food condition for zooplankton, data on chlorophyll, HNF, and bacteria were used, whereas for Size, data on mean water depth and surface area of the ponds were used. Direct geometric distances between ponds were calculated, and the spatial Distance matrix was constructed of pairwise direct distances between ponds (Appendix 2). We did not include fish community structure within the environmental matrices, because a preliminary analysis indicated that the similarity of zooplankton communities did not significantly differ between ponds with or without planktivorous fish, such as bluegill sunfish Lepsmis macrochirus.

Zooplankton abundance data were summarized into a matrix of pairwise Bray-Curtis dissimilarities between ponds. Data for the dominant species are presented in Appendix 3. Simple linear regression was used to identify the best predictors of dissimilarities between zooplankton communities. The dependent variable of the Bray-Curtis dissimilarities between communities was then regressed separately against all ecological factors (All matrix), spatial distance between sites (Distance matrix), and all ecological factors and spatial distances combined. Because of nonindependence of the data, significance was tested using randomization tests.

Pearson's correlation coefficients between the zooplankton and predictor matrices were tested using partial Mantel tests with 999 permutations (Bonnet \& Van de Peer 2002). A general linear model (GLM) was conducted to estimate the effects of local environmental factors and direct distance on dissimilarity of zooplankton communities (Wood 2004). The GLM model was constructed as follows:

(Dissimilarity of zooplankton communities) $=$ $X_{1}($ Factor 1$)+X_{2}($ Factor 2$)+X_{3}($ Factor 3$)+$ $X_{4}($ Factor 4$)+X_{5}($ Factor 5$)+X_{0}$

where Factors 1 to 5 were the following matrices of predictor factors: All, Water, Food, Size, and Distance. $\mathrm{X}_{1}$ to $\mathrm{X}_{5}$ are the mean coefficients of each factor, and $\mathrm{X}_{0}$ is the mean intercept. We tested all combinations of factors and selected the best 8 GLMs using Akaike's Information Criterion (AIC).

Finally, we performed variance partitioning within a redundancy analysis to separately estimate the effects of environmental factors and distance on zooplankton community dissimilarity (Peres-Neto et al. 2006). All statistical tests were performed using R v.2.10.0 (R Development Core Team 2009), with the 'vegan' package. 


\section{RESULTS}

\section{Correlations between matrices}

Correlations between the zooplankton matrices and the 5 predictor matrices (All, Water, Food, Size, Distance) differed between the 2 types of ponds (Table 1 ). All of the factors were more strongly correlated for unconnected ponds than for connected ponds. In both types of pond, the correlations between Distance and the other 4 environmental matrices were weak (Table 1); thus, the distance between ponds and the environmental variables did not appear to interactively affect zooplankton communities.

\section{Relationships between zooplankton communities and the 5 predictors}

For unconnected ponds, the dissimilarity of zooplankton communities was significantly related to Distance and All conditions $(r=0.373$ and 0.361, respectively, $\mathrm{p}<0.01$ ) (Fig. 2). In contrast, for connected ponds, the community dissimilarity was not strongly related to Distance or All conditions $(r=0.119$ and 0.102, respectively, p > 0.1) (Fig. 2). The regressions between the community dissimilarities and Water conditions did not markedly differ between the 2 types of pond ( $\mathrm{r}=0.288$ and 0.293 , respectively, $\mathrm{p}<0.1$ ) (Fig. 3). Similarly, regressions between the dissimilarity of communities and the matrices of Food and Size did not differ greatly between the 2 types of ponds $(\mathrm{r}=$ 0.122 and 0.083 for Food, $r=0.264$ and 0.209 for Size, $\mathrm{p}>0.1$; Fig. 3). Variance partitioning indicated that the All environmental factor and Distance explained equal proportions of the variance in zooplankton communities (Fig. 4). These proportions were higher for unconnected compared to connected ponds (Fig. 4). Variance partitioning was also conducted for the conditions of Water, Food, and Size; however, these factors explained less than $0.05 \%$ of the dissimilarity in zooplankton communities (data not shown).

\section{GLM results}

We also tested the effects of local environmental factors and direct distance on the dissimilarity of zooplankton communities using GLM (Table 2). For unconnected ponds, the best GLM indicated that the dissimilarity of zooplankton communities was determined by All conditions and Distance. The best 7 models included Distance as a predictor, and almost all factors in the best 8 models were significant $(p<0.05)$. For connected ponds, the best GLM predicting the dis-
Table 1. Pearson's correlation coefficients from partial Mantel tests between zooplankton dissimilarity matrices and matrices of 5 environmental factors (Distance, All, Water, Food, Size) and between a distance matrix (Distance) and the other 4 environmental matrices for unconnected $(\mathrm{n}=9)$ and connected $(n=9)$ ponds. Water, Size, and Food indicate dissimilarity matrices of the conditions of water, pond size, and food sources, respectively. The All matrix includes all of the environmental variables from the latter 3 matrices. Values in bold indicate significant coefficients $(p<0.01)$ from the partial Mantel test

\begin{tabular}{|lcc|}
\hline & Unconnected & Connected \\
\hline Zooplankton dissimilarity $\times$ & & \\
Distance \& All & $\mathbf{- 0 . 4 5 6}$ & 0.078 \\
All \& Distance & $\mathbf{- 0 . 4 4 5}$ & -0.010 \\
Water \& Distance & $\mathbf{- 0 . 3 6 4}$ & -0.285 \\
Food \& Distance & -0.135 & -0.079 \\
Size \& Distance & -0.291 & 0.240 \\
Distance × All & -0.245 & -0.105 \\
Distance $\times$ Water & -0.228 & -0.069 \\
Distance $\times$ Food & -0.157 & 0.034 \\
Distance $\times$ Size & -0.075 & -0.178 \\
\hline
\end{tabular}

similarity of zooplankton communities included only Water conditions (Table 2). However, none of the factors in the best 8 models was significant ( $p>0.2)$.

\section{DISCUSSION}

Our results indicated that the communities found among unconnected ponds were significantly related to environmental and distance factors. Thus, patterns of zooplankton species occurrence and abundance were correlated with the spatial arrangement of the ecosystems and local environmental conditions. The present study detected influences of both mass-effect and species-sorting on zooplankton communities. In contrast, the communities among connected ponds were not related to any of the predictive factors. Thus, from both a mass-effect and species-sorting perspective, increasing ecosystem connectivity strongly affected the metacommunity status as well as the influence of important environmental factors within the local community.

Patterns of zooplankton abundance were correlated with distance and environmental conditions. These findings are also supported by previous abundance studies on stream and pond invertebrates tested according to the mass-effect and species-sorting theories (e.g. Cottenie \& De Meester 2004, Thompson \& Townsend 2006). A series of studies has reported limited or no support for the mass-effect theory, however, the majority of these studies focused on sessile organisms (e.g. McGill 2003, Adler 2004, Wootton 2005). Thompson \& Townsend (2006) expected that local ecological 
Fig. 2. Relationships between percent dissimilarity of zooplankton communities (Bray-Curtis dissimilarity) and either distance between unconnected (O) and connected $(\bullet)$ ponds or dissimilarity of all environmental factors (see 'Materials and methods: connectivity of ponds'). Lines indicate simple linear regressions
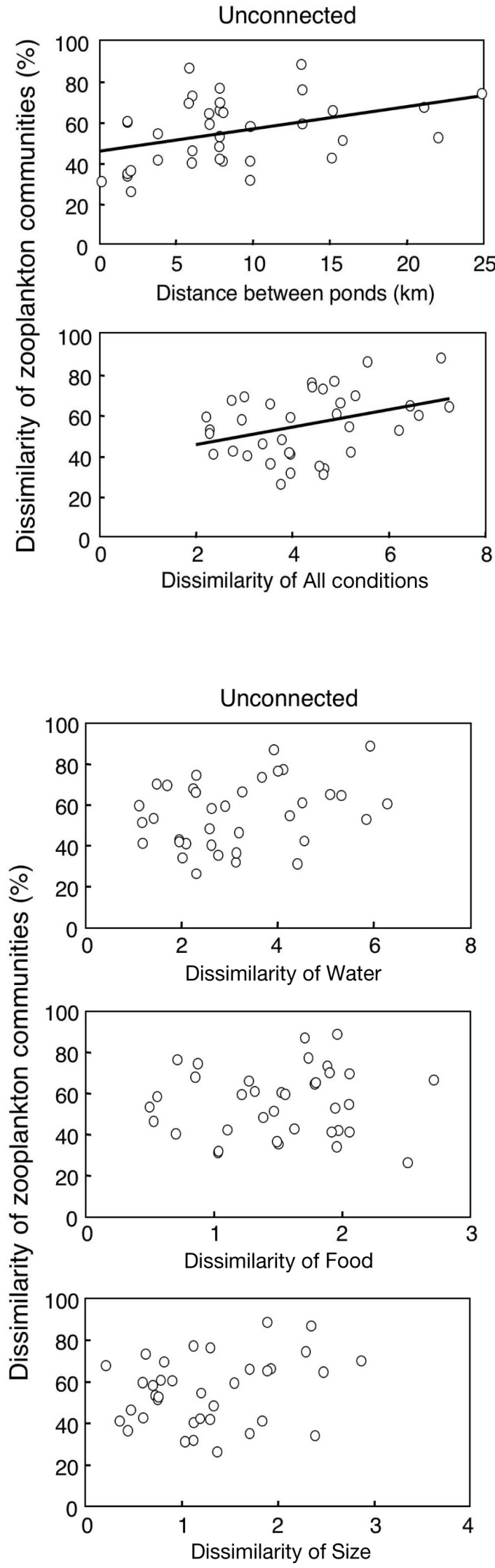

Connected
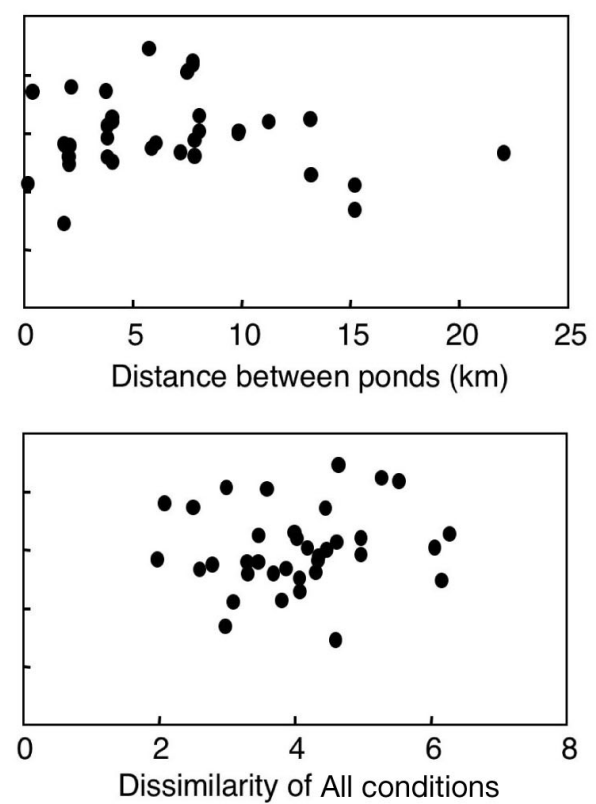

Connected
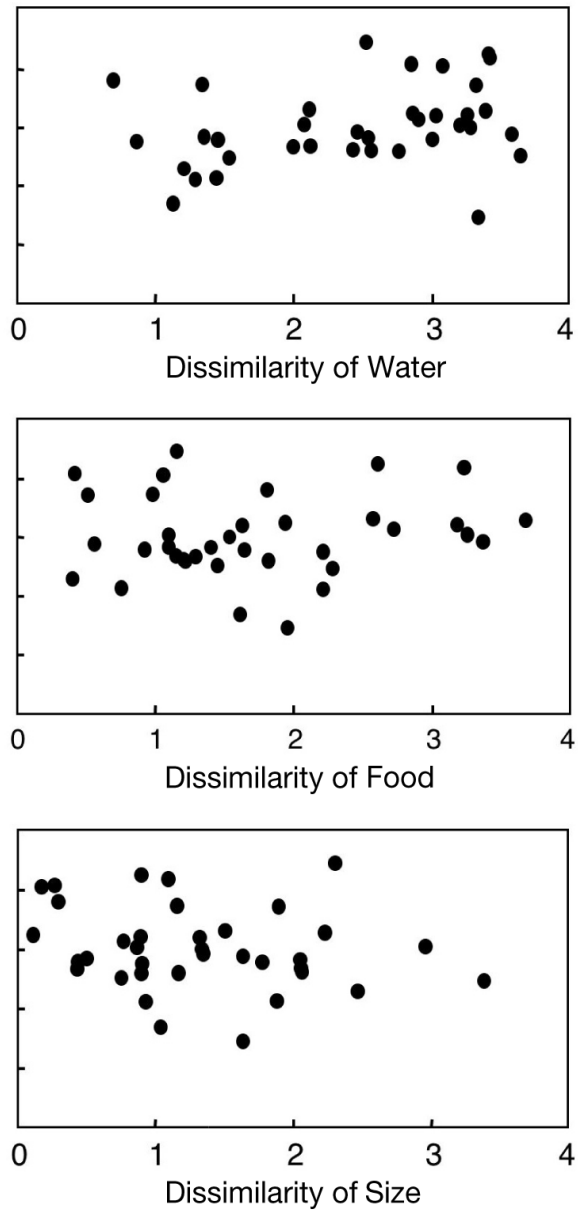

Fig. 3. Relationships between percent dissimilarity of zooplankton communities (BrayCurtis dissimilarity) and dissimilarity of 3 environmental factors (Water, Food, and Size; see 'Materials and methods: statistical analyses') 


\section{Unconnected Ponds}

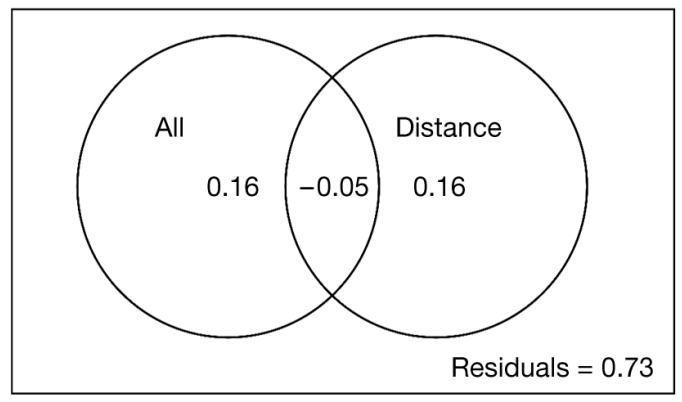

Connected Ponds

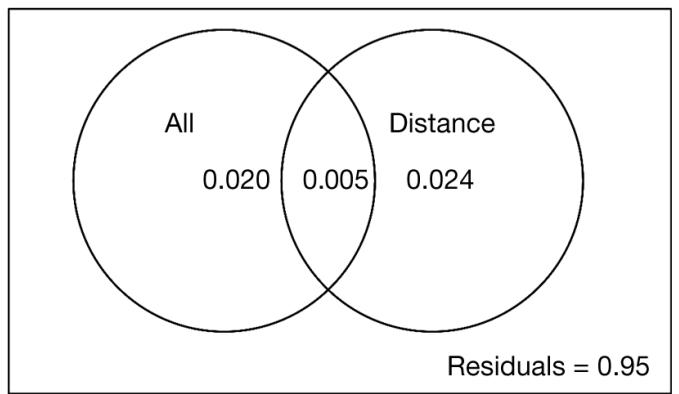

Fig. 4. Variance partitioning plots for the effects of distance between ponds and the effects of dissimilarity of all environmental factors (All) on the dissimilarity of zooplankton communities. Values indicate the proportion of variance explained by the dissimilarity of environmental factors and spatial factors, and their residuals (see 'Materials and methods: statistical analyses')

Table 2. The best 8 general linear models (GLMs) based on Akaike's Information Criteria (AIC). All and Dist indicate dissimilarity of all conditions (the All matrix) and the direct distance between unconnected $(\mathrm{n}=9)$ and connected $(\mathrm{n}=9)$ ponds (the Distance matrix), respectively. Water, Size, and Food indicate dissimilarity matrices of the conditions of water, pond size, and food sources. Values in bold indicate significant factors $(\mathrm{p}<0.05)$

\begin{tabular}{|lc|}
\hline Best 8 GLMs & AIC \\
\hline Unconnected & \\
$\mathbf{4 . 9 7} \times($ All $)+\mathbf{1 . 1 0} \times($ Dist $)+\mathbf{2 5 . 3}$ & 294.8 \\
$\mathbf{3 . 5 4} \times($ Water $)+5.62 \times($ Size $)+\mathbf{1 . 0 6} \times($ Dist $)+\mathbf{2 8 . 7}$ & 297.3 \\
$\mathbf{3 . 8 6} \times($ Water $)+\mathbf{1 . 0 6} \times \mathbf{( D i s t})+\mathbf{3 4 . 8}$ & 297.6 \\
$\mathbf{3 . 8 0} \times($ Water $)+3.29 \times($ Food $)+\mathbf{1 . 1 2} \times(\mathbf{D i s t})+\mathbf{2 . 9 5}$ & 299.1 \\
$\mathbf{3 . 8 6} \times($ Water $)+\mathbf{1 . 0 6} \times \mathbf{( D i s t})+\mathbf{3 4 . 8}$ & 299.2 \\
$6.51 \times($ Size $)+\mathbf{0 . 9 6} \times(\mathbf{D i s t})+\mathbf{3 9 . 5}$ & 299.5 \\
$\mathbf{0 . 9 5} \times(\mathbf{D i s t})+\mathbf{4 7 . 8}$ & 300.7 \\
$\mathbf{4 . 3} \times($ All $)+\mathbf{3 7 . 7}$ & 301.5 \\
Connected & \\
$4.70 \times($ Water $)+49.5$ & 291.7 \\
$4.36 \times($ Water $)-3.12 \times($ Size $)+54.4$ & 292.6 \\
$-3.70 \times($ Size $)+65.6$ & 292.8 \\
$4.56 \times($ Water $)-0.20 \times($ Dist $)+51.1$ & 293.6 \\
$1.55 \times($ All $)+54.6$ & 294.4 \\
$-0.29 \times($ Dist $)+62.8$ & 294.5 \\
$1.32 \times($ All $)-0.23 \times($ Dist $)+57.1$ & 296.6 \\
$3.80 \times($ Water $)+3.29 \times($ Food $)+1.12 \times($ Dist $)+29.5$ & 298.1 \\
\hline
\end{tabular}

conditions would more strongly affect aquatic insect communities than sessile organisms, as aquatic insects can actively select suitable habitats by choosing oviposition sites (e.g. Timm 1994, Winterbourn 2003). For zooplankton communities, most species exhibit a diapause stage and then hatch when conditions in their lake or pond are suitable (Brendonck \& De Meester 2003). Thus, the relationships between local ecological conditions and zooplankton communities might be stronger than that for sessile organisms due to the diapause stage of the zooplankton life cycle. Previous studies have revealed numerous important local conditions that affect zooplankton diversity: lake morphology (Keller \& Conlon 1994), productivity (Dodson et al. 2000), water quality (Jeppesen et al. 2000, Cottenie et al. 2001), and interspecific competition (Shurin 2000). In this study, the All condition was the most influential matrix for the dissimilarity of zooplankton communities. Therefore, it was the combination of several factors that affected the species composition and abundance of zooplankton in our study ponds.

Connectivity alters species' dispersal rates and provides a species pool to the entire community (Gilbert et al. 1998, Gonzalez et al. 1998, Gonzalez \& Chaneton 2002). The connectivity of our systems also provided a community species pool and influenced the relationships between community dissimilarity and the predictive environmental factors. This finding is likely related to the fact that high connectivity permits access to a larger pool of species, and as a result, zooplankton species diversity is often strongly reflected by the community of the entire species pool. Cottenie \& De Meester (2003) found no clear relationship between connectivity and differences in local species diversity of cladocerans. Therefore, connectivity may not directly affect local species diversity; it may instead indirectly influence the relationships between species diversity and environmental factors. Van de Meutter et al. (2007) suggested that the dispersal mode of species, and not passive dispersal via connections between ponds, strongly affects the metacommunity structure of benthic invertebrates. On the other hand, Cottenie \& De Meester (2004) reported that zooplankton have a much higher probability of being passively transported with flow through a pond system than do invertebrates living on macrophytes. Thus, the connectivity of systems may not create strong mass effects within metacommunities with low passive dispersal (e.g. benthic species).

In this study, we demonstrated that zooplankton community structure was determined by dispersal and local ecological conditions in artificially connected ponds, likely because the zooplankton life cycle includes a diapause stage. The connectivity of ecosystems also strongly affected dispersal within the zooplankton metacommunity as well as local ecological 
conditions. We also discussed these anthropogenic impacts on ecosystem connectivity. However, our results also indicated that changes in system connectivity can strongly affect metacommunity dynamics. To conserve local communities as well as the metacommunity as a whole, attention must be paid to the connectivity of systems to accurately estimate metacommunity dynamics within natural ecosystems.

Acknowledgements. We thank 4 anonymous reviewers for their helpful comments on an early version of the manuscript. We also thank A. Kajimoto, T. Ando, T. Yamamoto, W. Izumi, I. Ninomiya, and N. Nishihara for field sampling and sample preparations. This study was supported by a grant from the Japan Society for the Promotion of Science to H. D. and the Global COE program at Ehime University.

\section{LITERATURE CITED}

Adler PB (2004) Neutral models fail to reproduce observed species-area and species-time relationships in Kansas grasslands. Ecology 85:1265-1272

Bonnet E, Van de Peer Y (2002) ZT: a software tool for simple and partial Mantel tests. J Stat Softw 7:1-12

Brendonck L, De Meester L (2003) Egg banks in freshwater zooplankton: evolutionary and ecological archives in the sediment. Hydrobiologia 491:65-84

Caron DA (1983) Technique for enumeration of heterotrophic and phototrophic nanoplankton, using epifluorescence microscopy, and comparison with other procedures. Appl Environ Microbiol 46:491-498

> Cottenie K, De Meester L (2003) Connectivity and cladoceran species richness in a metacommunity of shallow lakes. Freshw Biol 48:823-832

Cottenie K, De Meester L (2004) Metacommunity structure: synergy of biotic interactions as selective agents and dispersal as fuel. Ecology 85:114-119

Cottenie K, Michels E, Nuytten N, De Meester L (2001) Zooplankton community structure and environmental conditions in a set of interconnected ponds. Hydrobiologia 442:339-350

> Dodson SI, Arnott SE, Cottingham KL (2000) The relationship in lake communities between primary productivity and species richness. Ecology 81:2662-2679

Gilbert F, Gonzalez A, Evans-Freke I (1998) Corridors maintain species richness in the fragmented landscapes of a microecosystem. Proc Biol Sci 265:577-582

Gilpin ME, Hanski IA (1991) Metapopulation dynamics: empirical and theoretical investigations. Academic Press, London

Gonzalez A, Chaneton EJ (2002) Heterotrophic species extinction, abundance and biomass dynamics in an experimentally fragmented microecosystem. J Anim Ecol 71:594-602

Gonzalez A, Lawton JH, Gilbert FS, Blackburn TM, EvansFreke I (1998) Metapopulation dynamics, abundance, and distribution in a microecosystem. Science 281:2045-2047

Holyoak M, Leibold MA, Holt RD (2005) Metacommunities: spatial dynamics and ecological communities. The University of Chicago Press, Chicago, IL

Jeppesen E, Jensen JP, Søndergaard M, Lauridsen T, Landkildehus F (2000) Trophic structure, species richness and biodiversity in Danish lakes: changes along a phosphorus gradient. Freshw Biol 45:201-218

Katano I, Negishi JN, Minagawa T, Doi H, Kawaguchi Y, Kayaba Y (2009) Longitudinal macroinvertebrate organization over contrasting discontinuities: effects of a dam and a tributary. J N Am Benthol Soc 28:331-351

Keller W, Conlon M (1994) Crustacean zooplankton communities and lake morphometry in precambrian shield lakes. Can J Fish Aquat Sci 51:2424-2434

Layman CA, Quattrochi JP, Peyer CM, Allgeier JE (2007) Niche width collapse in a resilient top predator following ecosystem fragmentation. Ecol Lett 10:937-944

Leibold MA, Miller TE (2004) From metapopulations to metacommunities. In: Hanski I, Gaggiotti OE (eds) Ecology, genetics, and evolution of metapopulations. Elsevier Academic Press, San Diego, CA, p 133-150

Leibold MA, Holyoak M, Mouquet N, Amarasekare P and others (2004) The metacommunity concept: a framework for multi-scale community ecology. Ecol Lett 7:601-613

> McGill BJ (2003) A test of the unified neutral theory of biodiversity. Nature 422:881-885

> Moran R, Porath D (1980) Chlorophyll determination in intact tissues using N, N-dimethylformamide. Plant Physiol 65: 478-479

> Mouquet N, Loreau M (2002) Coexistence in metacommunities: the regional similarity hypothesis. Am Nat 159:420-426

> Peres-Neto PR, Legendre P, Dray S, Borcard D (2006) Variation partitioning of species data matrices: estimation and comparison of fractions. Ecology 87:2614-2625

Porter KG, Feig YS (1980) The use of DAPI for identifying and counting aquatic microflora. Limnol Oceanogr 25:943-948

R Development Core Team (2009). R: a language and environment for statistical computing. R Foundation for Statistical Computing, Vienna

> Shurin JB (2000) Dispersal limitation, invasion resistance, and the structure of pond zooplankton communities. Ecology 81:3074-3086

Thompson R, Townsend C (2006) A truce with neutral theory: local deterministic factors, species trait and dispersal limitation together determine patterns of diversity in stream invertebrates. J Anim Ecol 75:476-484

Tilman D (1982) Resource competition and community structure. Princeton University Press, Princeton, NJ

Timm T (1994) Reasons for the shift in dominance between Simulium vernum and Simulium ornatum (Diptera, Simuliidae) along the continuum of an unpolluted lowland stream. Arch Hydrobiol 131:199-210

Tokeshi M (1999) Species coexistence: ecological and evolutionary perspectives. Blackwell Publishing, Oxford

> Urban MC (2004) Disturbance heterogeneity determines freshwater metacommunity structure. Ecology 85:2971-2978

Van de Meutter F, De Meester L, Stoks R (2007) Metacommunity structure of pond macroinvertebrates: effects of dispersal mode and generation time. Ecology 88:1687-1695

- Vanschoenwinkel B, De Vries C, Seaman M, Brendonck L (2007) The role of metacommunity processes in shaping invertebrate rock pool communities along a dispersal gradient. Oikos 116:1255-1266

Wilson DS (1992) Complex interactions in metacommunities, with implications for biodiversity and higher levels of selection. Ecology 73:1984-2000

Winterbourn MJ (2003) Habitat segregation and nymphal life history of two Nesameletus species (Ephemeroptera: Nesameletidae) in a mountain stream. Aquat Insects 25:41-50

> Wood SN (2004) Stable and efficient multiple smoothing parameter estimation for generalized additive models. J Am Stat Assoc 99:673-686

> Wootton JT (2005) Field parameterization and experimental test of the neutral theory of biodiversity. Nature 433: 309-312

Yamamoto N, Yokoyama J, Kawata M (2007) Relative resource abundance explains butterfly biodiversity in island communities. Proc Natl Acad Sci USA 104:10524-10529 
Appendix 1. Local ecological conditions in the 18 connected (C1 to C9) and unconnected (U1 to U9) ponds. EC: electric conductivity; DOC: dissolved organic carbon; HNF: heterotrophic nanoflagellates

\begin{tabular}{|c|c|c|c|c|c|c|c|c|c|c|c|c|c|c|c|c|c|c|}
\hline Parameter & $\mathrm{C} 1$ & $\mathrm{C} 2$ & $\mathrm{C} 3$ & $\mathrm{C} 4$ & C5 & C6 & $\mathrm{C} 7$ & $\mathrm{C} 8$ & C9 & U1 & $\mathrm{U} 2$ & U3 & $\mathrm{U} 4$ & U5 & U6 & U7 & U8 & U9 \\
\hline Surface area $\left(\mathrm{m}^{2}\right)$ & 2201 & 8793 & 23466 & 5206 & 13631 & 2592 & 3633 & 4801 & 1451 & 26948 & 7902 & 985 & 14831 & 3657 & 6621 & 18401 & 2802 & 2392 \\
\hline Mean depth (m) & 5.0 & 3.3 & 6.5 & 2.5 & 5.0 & 1.5 & 3.0 & 7.1 & 3.0 & 4.7 & 2.8 & 2.0 & 4.0 & 2.6 & 4.1 & 3.2 & 3.0 & 2.8 \\
\hline $\begin{array}{l}\mathrm{NO}_{3}^{-}+\mathrm{NO}_{2}^{-} \\
\left(\mu \mathrm{mol} \mathrm{l}^{-1}\right)\end{array}$ & 66.6 & 0.1 & 13.2 & 0 & 11.8 & 0 & 11 & 12.2 & 48.4 & 4.4 & 10.5 & 11.8 & 7.4 & 0 & 7.6 & 4.6 & 0 & 13.7 \\
\hline $\mathrm{NH}_{4}{ }^{+}\left(\mu \mathrm{mol} \mathrm{l} l^{-1}\right)$ & 3.9 & 0.6 & 0.6 & 0.7 & 6.6 & 0.9 & 0.7 & 7.3 & 0.8 & 9.6 & 5.1 & 11 & 55 & 1 & 12.6 & 31 & 1.1 & 5.6 \\
\hline $\mathrm{PO}_{4}{ }^{3-}\left(\mu \mathrm{mol} \mathrm{l} l^{-1}\right)$ & 0.1 & 0.7 & 0.1 & 0.1 & 1.7 & 0.2 & 0.3 & 0.1 & 0.1 & 0.4 & 0.1 & 0.1 & 0.3 & 0.1 & 0.5 & 0.2 & 0.1 & 0.1 \\
\hline $\mathrm{SiO}_{2}^{-}\left(\mu \mathrm{mol} \mathrm{l} l^{-1}\right)$ & 226.7 & 212.9 & 223.8 & 212 & 140.2 & 1.5 & 55.6 & 537.9 & 183.4 & 245.7 & 57.5 & 143.5 & 185.6 & 187.3 & 76.5 & 264.4 & 134.6 & 223.8 \\
\hline Secchi depth $(\mathrm{cm})$ & 80 & 45 & 240 & 60 & 150 & 70 & 40 & 270 & 70 & 60 & 50 & 200 & 40 & 40 & 90 & 60 & 20 & 90 \\
\hline $\mathrm{pH}$ & 7.1 & 9.6 & 8 & 7.6 & 7.1 & 9 & 9.9 & 7.6 & 8.3 & 6.5 & 7.3 & 7.6 & 7.9 & 8.6 & 7.3 & 8.2 & 9.6 & 8.3 \\
\hline $\mathrm{EC}\left(\mathrm{S} \mathrm{m}^{-1}\right)$ & 168 & 182 & 105 & 100 & 105 & 182 & 220 & 114 & 200 & 187 & 140 & 82 & 135 & 139 & 135 & 149 & 180 & 210 \\
\hline $\mathrm{DOC}\left(\mathrm{mg} \mathrm{l}^{-1}\right)$ & 2.6 & 2.2 & 1.9 & 3.2 & 2.8 & 3.5 & 2.6 & 2.6 & 2.7 & 4.1 & 1.8 & 1.7 & 3.7 & 4.7 & 3.6 & 9 & 8.1 & 3.1 \\
\hline Chl $a\left(\mu g l^{-1}\right)$ & 102.7 & 111.8 & 14.9 & 44.8 & 18.5 & 37.4 & 60.5 & 4.4 & 42.2 & 18.1 & 13.2 & 2.7 & 8.8 & 14.8 & 51.6 & 42.2 & 55.7 & 21.9 \\
\hline $\begin{array}{l}\text { Bacteria } \\
\left(10^{6} \text { cells } 1^{-1}\right)\end{array}$ & 3.4 & 2.5 & 1.7 & 4.8 & 6.3 & 11.5 & 6.2 & 6.5 & 4.5 & 2.8 & 9 & 6.3 & 10.7 & 6.5 & 4.1 & 4.2 & 4 & 3.7 \\
\hline $\begin{array}{l}\text { HNF } \\
\left(10^{4} \text { cells } 1^{-1}\right)\end{array}$ & 4.2 & 2.3 & 5.3 & 2 & 0.8 & 7.5 & 5.9 & 1.1 & 0.5 & 3.6 & 0.4 & 0.1 & 1.1 & 0.8 & 3.9 & 8 & 4.9 & 2.5 \\
\hline
\end{tabular}




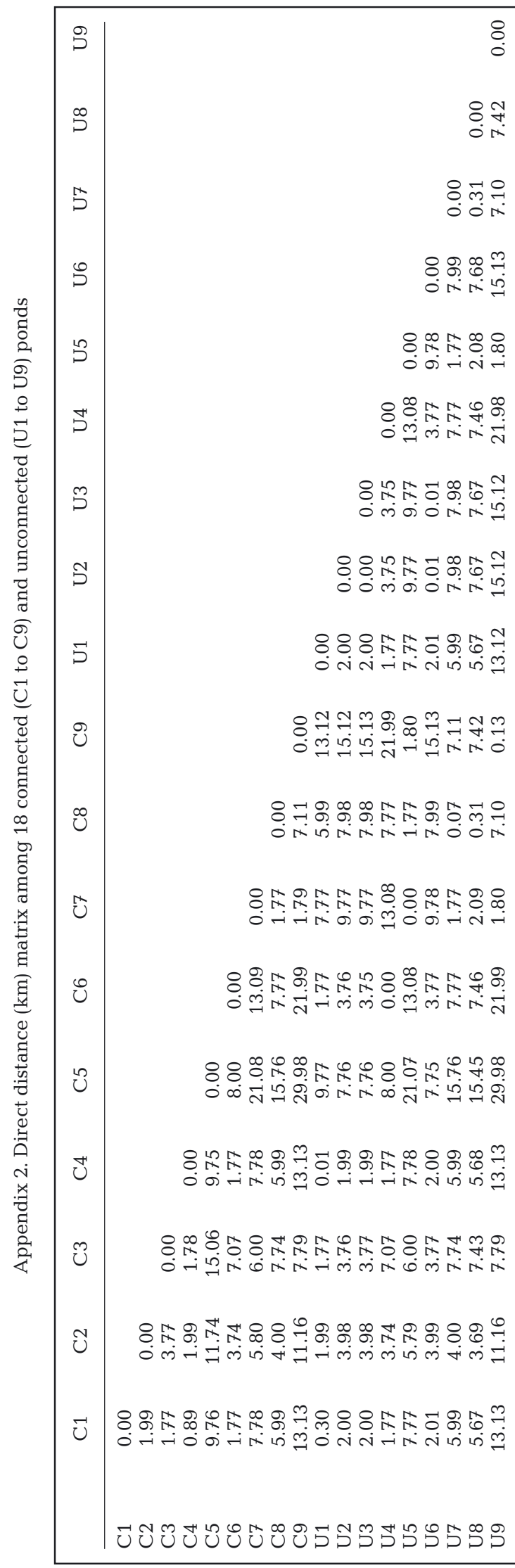

Editorial responsibility: Hans Heinrich Janssen, Oldendorf/Luhe, Germany

\begin{tabular}{|c|c|c|c|c|c|c|}
\hline$\stackrel{9}{\rho}$ & | & 1 & 1 & 1 & 111 & 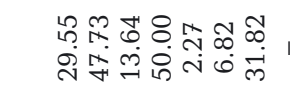 \\
\hline$\stackrel{\infty}{\rho}$ & 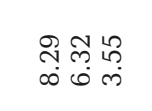 & 1 & \&্র & $\stackrel{\infty}{\stackrel{\infty}{h}}$ & 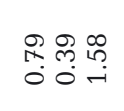 & 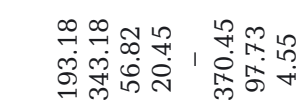 \\
\hline 今 & 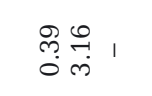 & $\begin{array}{l}0 \\
0 \\
0\end{array}$ & 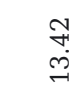 & $\underset{\substack{n\\
}}{2}$ & $\begin{array}{l}\mathscr{R} \\
0 \\
0\end{array}$ & 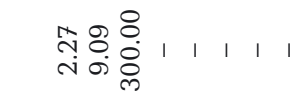 \\
\hline \% & , & 1 & 1 & 1 & 111 & 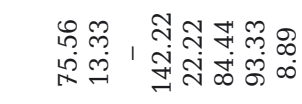 \\
\hline 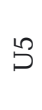 & 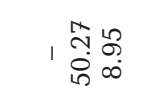 & 1 & 1 & I & $\stackrel{\infty}{\stackrel{\infty}{\rightarrow}} 11$ & 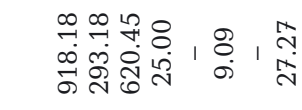 \\
\hline 官 & 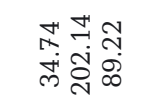 & 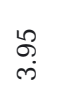 & 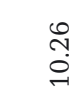 & $\begin{array}{l}\stackrel{0}{0} \\
\stackrel{+}{\circ}\end{array}$ & $\begin{array}{lll}0 & 0 \\
\dot{m} & & 0 \\
0\end{array}$ & 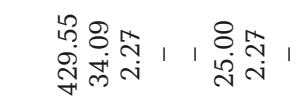 \\
\hline p & 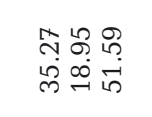 & $\underset{i}{\vec{i}}$ & 1 & I & 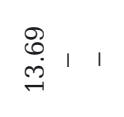 & 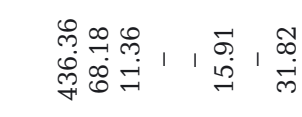 \\
\hline S & $\vec{N}, \mid \stackrel{\infty}{\infty}$ & 1 & $\underset{\text { సै }}{\mathrm{i}}$ & 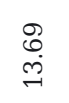 & $1 \quad 11$ & 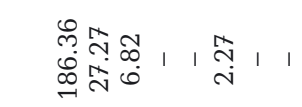 \\
\hline 5 & $\stackrel{\substack{\infty \\
\hdashline}}{\stackrel{\infty}{\rightarrow}}$ & $\underset{\stackrel{P}{H}}{i}$ & $\stackrel{\overparen{ก}}{\rightarrow}$ & $\stackrel{\ddot{m}}{\ddot{m}}$ & 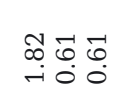 & 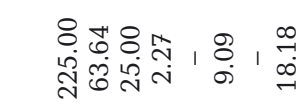 \\
\hline i & 峁 & $\exists$ & 1 & $\stackrel{\infty}{\stackrel{\infty}{\rightarrow-}}$ & 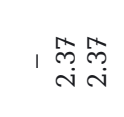 & 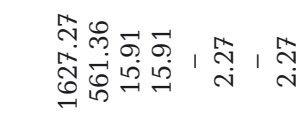 \\
\hline$\stackrel{\infty}{\cup}$ & | & 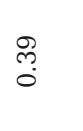 & $\begin{array}{l}\text { Ş } \\
\text { in }\end{array}$ & $\stackrel{\infty}{\stackrel{\infty}{-}}$ & 111 & 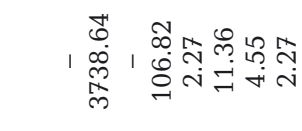 \\
\hline U & 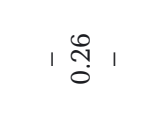 & 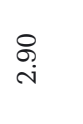 & 范 & $\underset{\sim}{\widetilde{T}}$ & 111 & 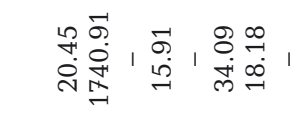 \\
\hline$\ddot{U}$ & 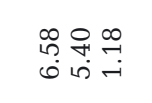 & I & $\stackrel{\leftrightarrow}{\bullet}$ & 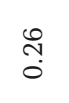 & $\stackrel{m}{\overrightarrow{0}} 11$ & 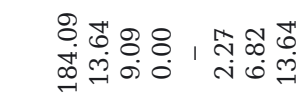 \\
\hline 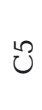 & 111 & $\underset{-}{8}$ & $\stackrel{\infty}{\leftrightarrow}$ & $\underset{\infty}{\infty}$ & 111 & 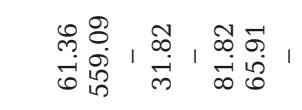 \\
\hline Ü & 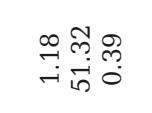 & 1 & 1 & 1 & | ֻ户 & 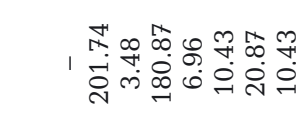 \\
\hline$\tilde{U}$ & 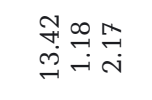 & ্ָণ & 1 & 1 & 111 & 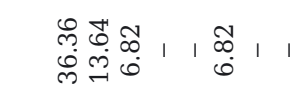 \\
\hline U & 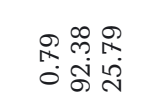 & $\stackrel{?}{\sim}$ & $\stackrel{\mathscr{F}}{\tilde{m}}$ & 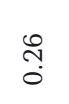 & 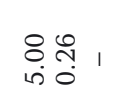 & 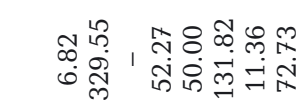 \\
\hline$\vec{U}$ & 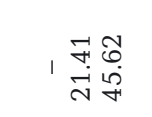 & $\underset{i}{ت}$ & $\begin{array}{l}\overrightarrow{6} \\
\dot{0}\end{array}$ & $\stackrel{?}{i}$ & 员员। & 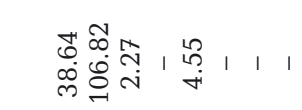 \\
\hline 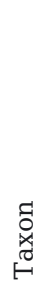 & 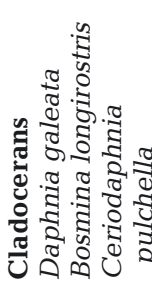 & 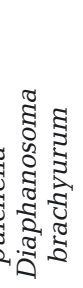 & 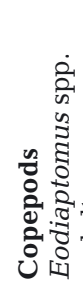 & 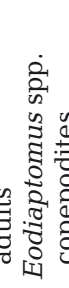 & 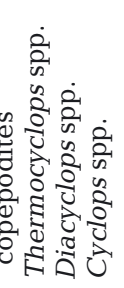 & 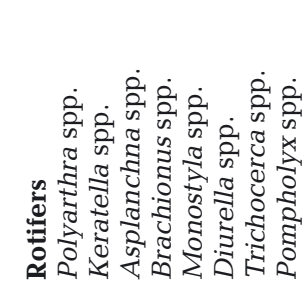 \\
\hline
\end{tabular}

